opinion poll held in June-July $2015(\mathrm{~N}=622, \mathrm{~A}<$ _0,05). In general, the citizens residing in Lutsk are estimated its «social climate» as quite acceptable (rating 3,5 from 5,0 points) and its fundamental problems are determined as follows: the maintenance of existing and construction of new children's playgrounds and athletic fields (10,4 \%); reconditioning of roads $(9,5 \%)$; reorganization of housing and utilities sector $(7,9 \%)$, etc. A sequence of urban pressing challenges is firmly established and typical giving grounds to the author's conclusion that the urban citizens are much more concentrated on the solutions of standard or traditional problems than to be focused on innovational or perspective issues such as the exploitation of exclusively e-Mobility within the city, recycling of waste, infrastructure development for getting around by any bike transport, organization of leisure time for people of old age, etc.).

As can be seen from the above, Lutsk is characterized as rather traditional city whose inhabitants are focused on the order and following standards.

Key words: problems of the city, condition of urban districts, social climate of the city, Lutsk.

Статтю отримано 08.07.2015 p.

УДК $316.77(075.8)$

\title{
Оксана Нехаенко
}

\section{Влияние социальных сетей на формирование массового политического сознания}

Обосновывается необходимость изучения политического сознания через средства массовой коммуникации как главного транслятора государственных идеологий, оказывающего значительное воздействие на политическое сознание, в первую очередь посредством знаков и символов. С целью определения факторов такого влияния проводится дискурс-анализ двух социальных сетей. Установлено, что используемые механизмы влияния и технические приёмы противоборствующих политических сил и направлений зачастую практически тождественны.

Ключевые слова: политическое сознание, социальные сети, идеология, социальный контроль, символическое измерение реальности.

Постановка научной проблемы и ее значение. Одной из главных характеристик современности является растущее влияние политического сознания (как особой формы общественного) на социальные явления и процессы. Как отмечает российский политолог Н. А. Баранов, такая тенденция обусловлена либерализацией политических систем [1]. Во-первых, подобный рост можно объяснить тем, что в конце XX в. происходили значительные изменения в мировой политической системе. Главным образом здесь подразумеваются трансформационные процессы в Восточной и Центральной Европе конца 1980 - начала 1990-х годов. Любые изменения социальной структуры актуализируют исследование природы и сущности характеристик политического сознания, его фундаментальных ценностей, поскольку переход от одной модели политического и социально-экономического устройства к другой обусловливает сдвиги в массовом политическом сознании. Во-вторых, значительное влияние на изменения сознания людей оказывает разветвлённая сеть средств массовой коммуникации. СМИ превратились в силу, способную формировать мышление и сознание масс: они выступают в качестве катализаторов и проводников идеологических мифов и паттернов. Проблема заключается в том, что при всей очевидности усиления влияния социально-психологических аспектов на общественную жизнь в целом и политические процессы в частности открытыми остаются следующие вопросы: 1) каковы предпосылки возникновения этой тенденции; 2) какова степень её влияния на формирование массового сознания; 3) какие инструменты воздействия наибольше востребованы сегодня в информационном пространстве; 4) какое место отводится политическим мифам в системе массового сознания.

Собственно, в этом заключается актуальность данной статьи: важно выявить инструменты, о которых говорилось выше, и осуществить попытку осмысления механизмов их функционирования. Кроме того, стоит отметить особую актуальность социологического подхода к изучению социальнополитического сознания (в частности, факторов формирования идеологических образцов и шаблонов). Сегодня, в условиях активного развития политических, рекламных и пропагандистских технологий, изучение особенностей функционирования СМК (в том числе и социальных сетей)

(C) Нехаенко О., 2015 
представляет немалый интерес для учёного-социолога и на первый план здесь выдвигается система знаков и символов, которые определяют направление и эффективность осуществляемых манипуляций.

Цель статьи - выявление и анализ способов воздействия на массовое политическое сознание. Соответственно, для достижения цели необходимо решить следующие задачи: во-первых, выяснить, как формируется политическое сознание; во-вторых, выявить, какие факторы наибольше способны влиять на формирование массового политического сознания в постсоветских странах, и отдельно охарактеризовать роль известных социальных сетей как особого инструмента информационнокоммуникационного воздействия на массовое сознание; в-третьих, определить функциональную связь идеологии и мифологии как двух сходных форм воплощения активности субъектов политического процесса.

Анализ исследований по этой проблеме. Исследования массового сознания (как в целом, так и его социально-политической формы) традиционно связывают с накопленными различными науками знаниями об институтах власти, неком политическом идеале и его влиянии на сознание людей, с изучением психологии масс, развитием массового общества, научным осмыслением роли масс в управлении государством. Современное социологическое изучение политического сознания связано с исследованием доминирующих в нём ценностей и ориентаций, роли политических институтов на формирование и развитие массового сознания, изучением политических конфликтов, политического участия и политического поведения масс, парадоксов и противоречий политического сознания граждан ${ }^{1}[5]$.

Эмпирическую базу исследования составляют публичные страницы («паблики») социальной сети «в Контакте»: «Українська революція» ${ }^{2}$ и «АнтиМайдан» ${ }^{3}$ (критерии отбора - противоположные по политическим ориентирам страницы с наибольшим количеством подписчиков) ${ }^{4}$. Уже в названиях этих сообществ заложена их политическая ориентация и идеологическая окрашенность групп (условно говоря, проукраинское сообщество «Українська революція» и пророссийское - «АнтиМайдан»).

Дискурс-анализу подвергались публикации («посты»), сделанные в течение одной недели (с 24 по 31 марта 2015 г.). Единицей анализа выступили понятия, выраженные в отдельных терминах или упоминаниях конкретных политических явлений или процессов. Нам было важно исследовать не только лексику и риторику сообществ в социальных сетях, но и визуальные компоненты (фотографии, картинки и иллюстрации, которыми сопровождаются посты, демотиваторы и т. д.). В данном случае дискурс-анализ даёт возможность выделения не только существенных характеристик социальной коммуникации, но и второстепенных, содержательных и формальных показателей; кроме того, анализ дискурса предполагает исследование конкретного пласта социальной реальности, а именно популярных сообществ в социальных сетях. Использование этого метода в исследовании направлено на обнаружение различных манипулятивных технологий в СМК. На этом основании осуществляется и авторская попытка выявления последствий их применения.

Изложение основного материала и обоснование полученных результатов исследования. Процесс формирования политического сознания предполагает осознание субъектами общества реалий политической жизни, характерных им ценностных ориентаций и интересов. Неоднородность политического сознания обусловлена неоднородностью и сложностью самого общества.

Будучи сформированным под воздействием бытия, сознание влияет на реальность посредством практики. В этом заключается некая обособленность социально-политического сознания от чисто психологического понимания сознания человека: оно не просто отражает действительность, а выступает осмысленным отношением субъекта к объекту отображения, определяет дальнейшую ориентацию деятельности в процессе практического выбора политических решений. Таким образом,

\footnotetext{
${ }^{1}$ Если представить все подходы в обобщенном виде, то можно выделить две господствующих позиции, относительно сущности политического сознания. Бихевиоральный подход рассматривает политическое сознание как форму рационального мышления индивида, всю совокупность его воззрений и представлений, которую он использует при реализации приписанных ему ролей и функций во властной сфере. Сторонники аксиологического подхода рассматривают социально-политическое сознание как уровень общественного мышления. Согласно этой позиции, в социально-политическое сознание входят разнообразные обыденные общечеловеческие воззрения и ценности.

${ }^{2}$ https://vk.com/uarevo

${ }^{3}$ https://vk.com/antimaydan

${ }^{4}$ Сообщества отобраны на основе статистики, предоставленной социальной сетью «в Контакте» и онлайн-сервисом, который доступен по ссылке: http://allsocial.ru/communities/ukrainskie?order=quantity
} 
сознание человека не только отражает мир и политические реалии, но и конструирует их, изменяет своими действиями.

Сегодня одним из главных и наиболее эффективных способов влияния на сознание человека является разветвлённая сеть средств массовой коммуникации. Политическая коммуникация в разы увеличила скорость продвижения информации, большой объем, краткость и образность сообений увеличивают интенсивность влияния на аудиторию. Социальные сети, порталы, блогосфера, форумы - это источник постоянно обновляющейся информации, мощно воздействующий на поле политики, если пользоваться терминологией П. Бурдье. Соответственно, они не могут не выступать в качестве объектов социологического анализа, если исследовательские задачи связаны с факторами формирования и изменения социально-политического сознания.

Прежде чем перейти к рассмотрению влияния социальных сетей на политическое сознание, раскроем, что представляют собой социальные сети и почему важно анализировать процессы, которые происходят в интернет-пространстве. Социальные сети - социальные структуры особого рода, состоящие из узлов (это могут быть как конкретные люди, так и сообщества, организации или же группы), связанные тем или иным способом с помощью социальных взаимоотношений [3]. Социальная сеть в Интернете представляет собой сайт, который является площадкой для взаимодействия между людьми, группами людей и организациями, где связи между этими узлами обеспечивает программная составляющая сайта. Такого рода средства массовой коммуникации заметно облегчают внедрение в сознание аудитории иллюзорной конструкции реальности, формирование социально-политических мифов. Согласно идее С. Г. Кара-Мурзы, миф может на протяжении длительного времени подменять действительность, в результате чего «реципиент воспринимает ее в соответствии с трактовкой мифа и действует, исходя из этого восприятия» [2, с. 58]. Так происходит моделирование сознания и, соответственно, изменение установок и социального поведения. Наличие политических мифов в обществе существенно упрощает процесс воздействия на общественное сознание. Соответственно, политическим силам важно обеспечить эффективную трансляцию этих мифов, а также их полную интериоризацию членами общества.

Непосредственному анализу в данной работе подвергнута социальная сеть «в Контакте». Выбор не случаен, поскольку, во-первых, социальные сети могут использоваться как гражданами для освещения какого-либо значимого вопроса, проблемы или события, так и политиками для наилучшего освещения деятельности или же в рамках проведения избирательных кампаний; вовторых, могут выступать в качестве инструмента мобилизации масс и координации протестных движений; в-третьих, социальные сети включают наибольшее количество зарегистрированных пользователей, по сравнению с другими интернет-сервисами, и, соответственно, характеризуются значительным охватом аудитории. По данным этой социальной сети, количество зарегистрированных пользователей только из Украины составляет более 22 млн. Еще одна популярная социальная сеть - «Facebook» - значительно отстает по количеству аккаунтов украинцев, которые составляют чуть более 3 млн. Кроме этого, отметим, что сообщество «в Контакте» имеет ограниченный круг пользователей, которые обладают доступом к администрированию пабликов, в отличие от Facebook, где информацию может публиковать («постить») любой зарегистрировавшийся пользователь, состоящий в сообществе. Соответственно публичные сообщества «в Контакте» гораздо ближе к отдельному, самостоятельному СМИ, и представляют собой уникальный кейс, который на нескольких простых примерах позволит нам рассмотреть то, как осуществляется трансляция политических мифов и идеологем посредством СМИ. Часто именно транслируемые паттерны определяют систему мировосприятия в данной сфере, задавая тем самым параметры представлений о пространстве и времени, корректируя набор сакральных персонажей и проектируя тенденции эволюции сложившихся мифологем. В большей части работающие внутри политикоидеологической системы, сюжеты и образы направлены на консолидацию социального бытия, выстраивание или сохранение общественной иерархии, на обеспечение устойчивости системы.

Перейдём непосредственно к рассмотрению содержания постов, которые опубликованы в указанных пабликах. В большинстве случаев лента сообщества представлена новостными сводками, ссылками на статьи и перепостами (размещение заимствованной публикации) с личных страниц пользователей сети или других общедоступных групп. Группа «Українська революція» ведется на украинском языке, но иногда в ленте можно увидеть и русскоязычные републикации («перепосты»). 
Важно отметить тот момент, что лишь половина постов носит новостной характер, в остальном же сообщения можно рассматривать как постулирующие и декларирующие.

В ходе анализа постов удалось выявить, что и в одном, и в другом интернет-сообществе используются практически одинаковые дискурсивные приёмы и механизмы воздействия на сознание. Наиболее часто используется навешивание ярлыков: субъекты социального взаимодействия разбиваются на два идеологически обусловленных лагеря: «бандеровцы» («фашисты», «укропы») и «сепаратисты» («ватники», «москали»). Следующим по степени востребования является приём «высмеивание лидера противоборствующей стороны». Он позволяет сконцентрировать негативные эмоции на конкретном предмете, что, в свою очередь, даёт возможность добиться наиболее сильной эмоциональной реакции. Заставить аудиторию ненавидеть в целом крупную социальную группу (тем более, если речь идёт о масштабах целого народа) не так легко: рациональные элементы социального сознания сопротивляются подобному гипертрофированному обобщению. Поэтому тем, кто воздействует на массовое социальнополитическое сознание, необходимо персонифицировать образ врага, выставляя главу противоборствующей стороны в негативном свете, например, обвиняя его в агрессии или неспособности принимать управленческие решения в силу интеллектуальной ограниченности и т. д. Манипуляторам важно не просто сформировать негативный образ правительства страны-противника, а сыграть на контрасте, противопоставляя конструированному негативному образу точно так же конструированный позитивный образ «своего правителя», который, наоборот, является рациональным, инициативным и т. д. Поэтому описываемый приём имеет двойственный характер, хотя нельзя не отметить, что его «позитивная» вариация встречается в исследуемых пабликах гораздо реже, чем «негативная».

Вместе с тем «подогревается» и нетерпимость к низовым представителям противоборствующих точек зрения. Формируются особые, характерные для социальных сетей (а позже и выходящие за их рамки) шаблоны и принципы общения. Введённое в недавнем прошлом в оборот публицистами словосочетание «hate of speech», или «риторика ненависти», в данном случае постепенно лишается публицистической маргинальности и переходит в статус точного описания наиболее востребованного элемента информационного воздействия, влияющего на восприятие ситуации аудиторией. Подчеркнём, что попытки строго «онаучнивать» данную метафору нами не осуществляются, но в рассматриваемом случае словосочетание позволяет емко выразить то, к чему сводится большинство постов: на первый план выдвигаются простые, но достаточно сильные эмоции, и здесь уместно говорить о своего рода архаизации массового сознания. Механизмы архаизации делают возможным осуществление массами быстрой семантической обработки значимой информации; при этом усвоение информации происходит почти всегда на бессознательной основе, «автоматически». Это и является неотъемлемым условием возникновения так называемого «языка вражды», который находит применение при использовании выражений и слов, в самом своем значении содержащих отрицательную оценку - «ярлыков». Эти слова и выражения могут быть использованы таким образом, что отрицательная оценка оказывается не в фокусе внимания, а подается как нечто само собой разумеющееся, вытекающее из самой сути дела и не допускающее дискуссии. С помощью использования подобных ярлыков в сознании моделируется стереотипный образ «другого» (чаще всего инвертированный в «чужого»). На тщательно подготовленном негативном фоне создается свой собственный пример, привлекательный и правильный. Единственное явное определение, которое всегда будет четко прослеживаться, - это связки «я и иной» или «мы и другие», многообразие трактовок которых будет сведено исключительно к противопоставлению.

Символическая языковая система действует и влияет на массовое сознание неуловимо для индивида. Слишком уж просто считывать предложенные установки и шаблоны, в которых яркий образ и метко подобранная форма точечно заменяют самостоятельный аналитический процесс. Интересно и то, что чем более негативна характеристика, тем быстрее она фиксируется в массовом сознании. И потому в повседневный дискурс вклиниваются те обороты и фразы, которые изначально использовались исключительно в рамках интернет-сообществ, они мощно укореняются в индивидуальном сознании, постепенно переставая восприниматься исключительно как сетевой сленг.

Очевидно, что идеологическое противостояние в социальных сетях закрепляется, в первую очередь, на уровне символов (вспомним, например, «флешмоб», когда пользователи социальных 
сетей массово ставили вместо фото профиля («аватарки») картинки с фоном, представленным цветами государственного флага Украины). Поэтому особая роль в нашем анализе отведена изучению символического измерения социальной реальности и того, каким образом она воспроизводится в интернет-пространстве. Политические символы конструируют настроения, являясь важнейшим фактором восприятия политических событий и процессов. С практической точки зрения, эффективность манипуляции символами определяет качество и скорость моделирования массового сознания, его соответствие конкретным историческим условиям. При кризисных трансформациях символы - это те элементы, на которые, в первую очередь, нацелены разрушительные силы масс, поскольку символы, хоть и не являются общественными институтами, но транслируют важнейшие смыслы, которые ассоциируются с теми или иными институциональными принципами. Однако поскольку борьба против институтов часто неэффективна (в силу устойчивости этой формы организации совместной деятельности людей), то протестный потенциал выплёскивается в разного рода борьбу с символами. Причём символы могут быть как персонифицированными, так и неперсонифицированными; в качестве символа может рассматриваться какое-либо историческое событие или процесс. Так, в группе «Українська революція» периодически появляются посты с изображением казаков.

Выводы и перспективы дальнейших исследований. Отметим, что эффективность зафиксированных исследованием приёмов воздействия на массовое социально-политическое сознание обеспечивает, на наш взгляд, такая особенность современных средств массовой коммуникации, как иллюзия плюрализма выбора. Миф об индивидуализме и свободном выборе источников информации подготавливает плодородную почву для политических манипуляций и моделирования политического сознания ${ }^{1}$.

Современные политические мифы формируются в среде информационного изобилия. При помощи социальных сетей у индивида искусственно создаются конкретные образы и представления, при этом все они не требуют критического осмысления и не приемлют сомнения. Напомним, что важное место в механизме влияния социальных сетей на установки и воззрения человека занимает взаимодействие между пользователями и авторитет. Все люди в соцсети делятся на друзей («френдов») и людей, которые не входят в список друзей. И хотя процесс взаимовлияния пользователей внутри сети остается предметом для дискуссии, мы всё же полагаем, что та информация, которая отображается в персональной ленте новостей, в определенной степени способна влиять на индивидуальное восприятие особенно, если информация повторяется с некоторой периодичностью.

Социальные сети могут быть действенными коммуникационными площадками, которые позволяют определить весь спектр общественного мнения, различия в позициях, и даже осуществлять гражданское управление. В то же время они являются мощным средством влияния на массовое сознание посредством знаков и символов. Информация, которая выдаётся дозами, фрагментарна, не является объемной и не требует глубокого анализа, способствуя формированию «клипового мышления» и, как следствие, мифологического типа мышления. К. Леви-Стросс отмечал, что «ничто не напоминает так мифологию, как политическая идеология» [цит. по: 6, с. 85], и допускал замену мифологии идеологией. В большинстве рассмотренных нами случаев публикуемые посты не являются чисто информативными, а выполняют идеологическую функцию, апеллируя к эмоциональной составляющей. Но при этом отметим, что они могут основываться не только на эмоциональном компоненте, но и на формальноубеждающем и другом воздействии, мощнейшим инструментом которого является язык.

\section{Источники и литература}

1. Баранов Н. А. Трансформация политического сознания современного российского общества [Электронный ресурс] / Н. А. Баранов // Политическая экспертиза. Политэкс. - 2007. - Т. 3, № 1. - С. 87-103. Режим доступа : http://www.politex.info/content/view/326/30/

2. Кара-Мурза С. Г. Манипуляция сознанием / С. Г Кара-Мурза. - М. : Алгоритм, 2004. -528 с.

3. Киселев Н. Социальные сети как инструмент PR [Электронный ресурс] / Н. Киселев. - 2008. - Режим доступа : http://pr-club.com/assets/files/pr_lib/pr_root/KisSocSeti.doc

4. Маркузе Г. Критическая теория общества : избр. работы по философии и социальной критике / Г. Маркузе / пер. с англ. А. А. Юдина. - М. : Астрель, 2011. - 382 с.

\footnotetext{
${ }^{1}$ Еще Г. Маркузе отмечал, что инновационные технологии превращают общество в тоталитарное, в его управление внедряются достаточно эффективные, но обманчивые методы социального контроля над индивидами. Новые технологии, находящиеся на службе у системы господства, упрощают восприятие людей, подавляют индивидуальность и внутреннюю свободу личности [4, с. 109-111].
} 
5. Соловьев А. И. Политология: Политическая теория, политические технологии : учеб. для студ. вузов /А. И. Соловьев. - М. : Аспект Пресс, 2006. - 559 с.

6. Флад К. Политический миф. Теоретическое исследование / К. Флад ; пер. с англ. А. Г. Георгиев. - М. : Прогресс-Традиция, 2004. - 264 с.

\section{References}

1. Baranov, N. A. (2007), "The transformation of the political consciousness of modern Russian society", Political expert: POLITEXP, Vol. 3, No. 1, Pp.87-103, http://www.politex.info/content/view/326/30/

2. Kara-Murza, S. G. (2004), "Manipulation of consciousness", M. : Algorithm, 528 p.

3. Kiselev, N. (2008), "Social Networks as a PR tool", http://pr-club.com/assets/files/pr_lib/ pr_root/KisSocSeti.doc

4. Markuze, G. (2011), "Critical theory of society: Selected works of philosophy and social criticism", M. : Astrel, $382 \mathrm{p}$.

5. Solovyov, A. I. (2006), "Political Science: Political Theory, Political Technologies” M. : Aspect Press, 559 p.

6. Flad, K. (2004), "Political myth. Theoretical study", M. : Progress-Tradition, 264 p.

Нехаснко Оксана. Вплив соціальних мереж на формування масової політичної свідомості. У статті обгрунтовано необхідність вивчення політичної свідомості через засоби масової комунікації, оскільки саме вони $є$ головними трансляторами державних ідеологій, наймогутнішим засобом впливу на масову свідомість. Такий вплив здійснюється, насамперед, за допомогою розгалуженої системи знаків і символів. Для виявлення факторів, які впливають на масову свідомість, та її особливостей у кризових суспільствах проведено дискурсаналіз двох соціальних мереж. Установлено, що використовувані механізми впливу й технічні прийоми в протистоянні політичних сил і напрямів, незалежно від їх змістовного аспекту, нерідко $є$ практично тотожними.

Ключові слова: політична свідомість, соціальні мережі, ідеологія, соціальний контроль, символічний вимір реальності.

Nehaenko Oksana. The Impact of Social Networks on the Formation of Mass Political Consciousness. The paper concerns political consciousness as a specific type of consciousness, its essence and close connection with political processes and phenomena. The term "political consciousness" is defined. It is stated that political consciousness should be studied in the framework of mass media as they present the main translator of state ideologies. Mass media are the most powerful means of influence on public consciousness. Such influence is exercised firstly through signs and symbols. The objective of the article is to point out the factors influencing mass consciousness and to determine which specificities are characteristic of consciousness in societies experiencing the state of crisis. In order to solve the set tasks quality methods and exactly discourse-analysis were used. We can state that the specificity of modern mass media is the idea of individualism and free choice of information sources but practically mass media and social nets present the arena where the struggle between political forces takes place. Social networks is an arena for confrontation between political forces and trends, regardless of their content aspect, the impact of the mechanisms used and the technical methods are practically identical. Social networks occupy a dominant position among the QMS, which makes it possible to say that today many social networks define the entire spectrum of public opinion, the differences in positions. Sometimes civil administration is carried out with their help.

Key words: political consciousness, social networks, ideology, social control, symbolical change of reality.

Статтю отримано 18.05.2015 p. 